\title{
Mammary alveolar cell as in vitro evaluation system for casein gene expression involved in glucose level
}

\author{
Young Tae Heo ${ }^{1, a}$, Woo Tae Ha, ${ }^{1, a}$, Ran Lee ${ }^{1}$, Won-Young Lee ${ }^{2}$, Ha Yeon Jeong ${ }^{3}$, \\ Kyu Chan Hwang ${ }^{4}$, and Hyuk Song ${ }^{1, *}$
}

\footnotetext{
* Corresponding Author: Hyuk Song

Tel: +82-2-2450-0562, E-mail: songh@konkuk.ac.kr

${ }^{1}$ Department of Stem Cell and Regenerative Biology, College of Animal Bioscience and Technology, Konkuk University, Seoul 143-701, Korea

${ }^{2}$ Division of Food Bioscience, RIBHS, College of

Biomedical and Health Sciences, Konkuk University,

Chung-ju 380-701, Korea

${ }^{3}$ Department of Animal Resources Development Dairy

Science Division, National Institute of Animal Science,

RDA, Cheonan 331-801, Korea

${ }^{4}$ Sooam Biotech Research Foundations, Seoul 152895 , Korea
}

a These authors and first author contributed equally to this work.

Submitted Jul 5, 2016; Revised Aug 8, 2016;

Accepted Sept 19, 2016
Objective: Glucose is an essential fuel in the energy metabolism and synthesis pathways of all mammalian cells. In lactating animals, glucose is the major precursor for lactose and is a substrate for the synthesis of milk proteins and fat in mammary secretory (alveolar) epithelial cells. However, clear utilization of glucose in mammary cells during lactogenesis is still unknown, due to the lack of in vitro analyzing models. Therefore, the objective of this study was to test the reliability of the mammary alveolar (MAC-T) cell as an in vitro study model for glucose metabolism and lactating system.

Methods: Undifferentiated MAC-T cells were cultured in three types of Dulbecco's modified Eagle's medium with varying levels of glucose (no-glucose: $0 \mathrm{~g} / \mathrm{L}$, low-glucose: $1 \mathrm{~g} / \mathrm{L}$, and high-glucose: $4.5 \mathrm{~g} / \mathrm{L}$ ) for $8 \mathrm{~d}$, after which differentiation to casein secretion was induced. Cell proliferation and expression levels of apoptotic genes, Insulin like growth factor-1 (IGF1) receptor, oxytocin receptor, $\alpha \mathrm{S} 1, \alpha \mathrm{S} 2$, and $\beta$ casein genes were analyzed at $1,2,4$, and $8 \mathrm{~d}$ after differentiation.

Results: The proliferation of MAC-T cells with high-glucose treatment was seen to be significantly higher. Expression of apoptotic genes was not affected in any group. However, expression levels of the mammary development related gene (IGF1 receptor) and lactation related gene (oxytocin receptor) were significantly higher in the low-glucose group. Expressions of aS1-casein, aS2-casein, and $\beta$-casein were also higher in the low-glucose treated group as compared to that in the no-glucose and high-glucose groups.

Conclusion: The results demonstrated that although a high-glucose environment increases cell proliferation in MAC-T cells, a low-glucose treatment to MAC-T cells induces higher expression of casein genes. Our results suggest that the MAC-T cells may be used as an in vitro model to analyze mammary cell development and lactation connected with precise biological effects.

Keywords: Glucose; Mammary alveolar (MAC-T) Cell; Insulin-like Growth Factor-1 (IGF-1); Oxytocin; Casein

\section{INTRODUCTION}

Glucose is a universal and essential fuel in the energy metabolism and synthesis pathways of all mammalian cells [1]. It is constantly and widely required at sufficient levels in the blood stream, and is metabolized by the process of glycolysis. In lactating animals, glucose is the major precursor for lactose and is a substrate for the synthesis of milk proteins and fat in mammary secretory (alveolar) epithelial cells. However, the mammary tissue is unable to synthesize glucose from other precursors due to the lack of the enzyme glucose-6-phosphatase. Therefore, glucose in blood is the alternative supply for its glucose needs [2].

The supply of glucose to mammary glands is a metabolic priority in lactating mammals, and 
the resulting glucose uptake by the mammary gland can account for as much as $60 \%$ to $85 \%$ of the total glucose that enters the blood [3,4]. Xiao and Cant [5] reported that $80 \%$ of glucose intake in blood is utilized for producing milk fat, lactose and $\mathrm{CO}_{2}$ [5]. The remaining $20 \%$ glucose is used for activating glucose receptors, enzymes and regulatory proteins [5]. However, the process of utilizing glucose for milk production is still unclear. Rulquin et al [6] reported that infusion of glucose directs circulating amino acids to the mammary gland, resulting in higher production of milk in dairy cows [6]. Although the future potential is unknown, Brown et al [7] demonstrated that higher energy and protein intake from 2 to 8 weeks of age increased parenchymal mass in mammary glands of heifer calves without increasing deposition of parenchymal fat [7]. Therefore, it is suggested that diet influenced histological development of mammary parenchyma and subsequent proliferation of ductal epithelial cells. In contrast, because glucose only plays a basic role in primary metabolism, surplus glucose is unnecessary or even adverse for lactation [8]. Additionally, because growing ruminants have the ability to adapt rapidly to variations in food intake linked metabolic changes, continuous food restriction followed by re-feeding shift energy and nitrogen metabolism [9]. Another study suggested that the rate of body weight gain has a minimal impact on the histological development of mammary ductal development [10]. These conflicting opinions may be due to lack of appropriate in vitro analyzing models of the lactation system, thus leading to a lack of understanding of the role of glucose in lactating metabolism.

There are limited cell lines which are derived from bovine mammary glands such as mammary alveolar (MAC-T) and bovine mammary epithelial (BME-UV1) cell lines [11]. Among them, the immortalized MAC-T cell is established by transfection with the SV40 T-antigen [12] and is known as a reliable cell line model with very similar responses for biochemicals and proteins including inflammation related proteins and hormones to primary mammary epithelial cells [13]. MAC-T cell is also assumed to be a typical in vitro model of the mammary gland because these cells have similar biochemical and morphological characteristics to mammary epithelial cells in vivo [14]. Therefore, this cell line has been widely used for analyzing bioactivities of hormones, cytokines and mammary extracts as well as for analyzing biological events such as proliferation, apoptosis, gene expression, cell signaling and lipogenesis [15-21]. Recently, application of bovine mammary epithelial cell lines has been extended and extensively studied for breast cancer, immune response, and hormone regulation during lactation and development of drugs [22,23].

Therefore, we propose that the MAC-T cell might be an appropriate in vitro model to test the effects of energy consumption related to lactogenesis. Thus, the hypothesis of this study is that different levels of glucose treatment to the MAC-T cell may affect lactating efficiency. To test this hypothesis, an objective of this study was to investigate the expression of $\alpha \mathrm{S} 1, \alpha \mathrm{S} 2$, and $\beta$-casein mRNA as markers of lactating levels after treatment with different levels of glucose. Additionally, levels of mRNA, which were related to lactation, regulatory, mammary development and mammary gland specific glucose transporter genes, were analyzed. Therefore, our study was conducted to test the reliability of MAC-T cell as an in vitro study model for glucose metabolism and lactating system.

\section{MATERIALS AND METHODS}

\section{Cell culture}

The MAC-T cells were cultured in three types of Dulbecco's modified Eagle's medium (DMEM; Hyclone, Waltham, MA, USA) based on concentration of glucose (no-glucose: $0 \mathrm{~g} / \mathrm{L}$, lowglucose: $1 \mathrm{~g} / \mathrm{L}$, and high-glucose: $4.5 \mathrm{~g} / \mathrm{L})$, containing $10 \%$ fetal bovine serum (FBS; Hyclone), $100 \mathrm{IU} / \mathrm{mL}$ penicillin, and 100 $\mu \mathrm{g} / \mathrm{mL}$ streptomycin (Sigma, St. Louis, MO, USA) at $37^{\circ} \mathrm{C}$ in an atmosphere of $5 \% \mathrm{CO}_{2}$ and air for $8 \mathrm{~d}$. For induction of differentiation, cells were detached with $0.05 \%$ of trypsin-ethylenediaminetetraacetic acid (Sigma, USA). The initial number of cells in each group was $5 \times 10^{4}$ cells/well in a 6-well plate and cultured for $4 \mathrm{~d}$, and then the cells in each group were split on additional 6-well plates on 4 and $5 \mathrm{~d}$. Induction of differentiation of MAC-T cells was conducted as we described previously [24]. Briefly, cells were cultured $\left(5 \times 10^{4}\right.$ cells/well in 6-well plate) in serum-free DMEM for $16 \mathrm{~h}$ and then cultured in high-glucose DMEM addition of 5\% FBS, $5 \mu \mathrm{g} / \mathrm{mL}$ insulin (Sigma, USA), 1 $\mu \mathrm{g} / \mathrm{mL}$ hydrocortisone (Sigma, USA), $5 \mu \mathrm{g} / \mathrm{mL}$ prolactin (PRL) (Sigma, USA) and $1 \mu \mathrm{M}$ retinoic acid (RA) (Sigma, USA) for $4 \mathrm{~d}$ and then divided to 6 -well plates on 4 and $6 \mathrm{~d}$. The medium was changed daily and mRNAs of cells were extracted at 1,2, 4, and $8 \mathrm{~d}$. Numbers of cells were counted using a hemocytometer after detachment and stained with $0.04 \%$ trypan blue (Gibco, Grand Island, NY, USA) diluted 1:1 with 1×phosphate-buffered saline.

\section{Quantitative real-time polymerase chain reaction}

Total RNA was isolated from MAC-T cells with RNAiso Plus reagent (Takara, Otsu, Japan). The cDNA was prepared with Superscript III (Invitrogen, Carlsbad, CA, USA) according to the manufacturer's instructions. Quantitative polymerase chain reaction (Q-PCR) was performed on a Bio-Rad CFX Connect optical module (Bio-Rad, Hercules, CA, USA) using SYBR Green (Toyobo, Osaka, Japan) as a marker for DNA amplification. The Q-PCR was performed with $2 \mu \mathrm{L}$ of DNA (input DNA was diluted 1:5) using 40 cycles of 3-step amplification. The primers used for PCR were as follows: Glyceraldehyde 3-phosphate dehydrogenase (GAPDH) (NM001034034), GGGTCATCATCTCTGCA CCT (forward), GGTCATAAGTCCCTCCACGA (reverse); Bcl-xL (NM001077486), CTCAGAGTAACCGGGAGCTG (forward), CCATTCACAGCAGGGCTATC (reverse); Bax (NM 
173894), TCTGACGGCAATTTCAACTG (forward), TGGGT GTCCCAAAGTAGGAG (reverse); Caspase 8 (NM001045970.2), TGAGGGCCCTGGGATTTTAT (forward), GTAGTTGTTACCAG AGGCGG (reverse); insulin like growth factor-1 (IGF1) receptor (NM001244612), AAGAACCATGCCTGCAGAAGG (forward), GGATTCTCAGGTTCTGGCCATT (reverse); Oxytocin receptor (NM174134.2), ATCCGCACGGTCAAGATG (forward), AGAG GAAGCGCTGCACAA (reverse); aS1-casein (BC109618), CAC TGAGTCAAAGGGAATTAAAG (forward), TGATGGCACT TACAGGAGA (reverse); aS2-casein (NM174528.2), CTGGAAT TAACTGCTTCTACCT (forward), TACTCTGCGATTTGTCTT ATTGA (reverse); $\beta$-casein (NM181008), CCTAACAGCCTCCC ACAAAA (forward), AGACTGGAGCAGAGGCAGAG (reverse); GLUT1 (NM_174602), CGGCTGCCCTGGATGTC (forward), GCCTGGGCCCACTTCAAA (reverse); GLUT4 (BC114082.1), GTCAACACAGTCTTCACCTTAGTCT (forward), CCAGGCCCAGGAGATGGA (reverse); GLUT8 (AY 208940), TTCAGCAGTCTCATGGAGGT (forward), TTTGGA GTCACAGGTAGGCT (reverse); GLUT12 (NM 001011683.2), CTTGTTAGTCCTGACCTGCC (forward), CTTCTGTGTTGG GGAGCAAT (reverse).

\section{Western blot}

The total secreted casein was obtained from the $4 \mathrm{~d}$ cultured media with induction of differentiation, and it was concentrated using a protein concentration kit (Merck Millipore, Darmstadt, Germany; 100196) according to the manufacturer's instruction. Fifty micrograms of protein from each sample was separated by $4 \%$ to $20 \%$ gradient gel (Bio-Rad, USA; $456-1094$ ) electrophoresis and transferred to polyvinylidene fluoride membranes (Bio-Rad, USA; 162-0177). The membrane was blocked in 1\% bovine serum albumin in tris-buffered saline plus $0.25 \%$ tween-20 (TBS-T) and incubated for $1 \mathrm{~h}$ at room temperature (RT) with dilutions of primary antibodies using anti-bovine Casein (1:2,000 dilution; Abcam, Cambridge, UK; ab166596). After washing the membrane three times for 5 min using TBS-T, goat anti-rabbit IgG-HRP (1:2,500 dilution; Santa Cruz Biotechnology, Texas, USA; SC-2004) was added for $1 \mathrm{~h}$ at RT. Protein expression was confirmed using enhanced chemiluminescence.

\section{Statistical analysis}

The general linear models procedure in the SAS software (SAS Institute Inc., Cary, NC, USA) was used to analyze the data from all experiments. Significant differences were determined using the Tukey multiple range test, and $\mathrm{p}<0.05$ was considered significant.

\section{RESULTS}

Proliferation of cells was observed daily in all groups both before and after induction of differentiation (Figure 1A). Results indicated that proliferation of cells in all groups were not significantly different until $2 \mathrm{~d}$, both before, and after induction of differentiation (Figure 1A, B, C). Proliferation of cells treated with high-glucose was significantly higher than that of no-glucose and low-glucose treated cells before differentiation induction (Figure 1B). However, no significant difference in proliferation rates was observed between low and high-glucose treatment (Figure 1C). These results indicate that former glucose environment may not affect present cell proliferation.

To test whether levels of glucose affect induction of apoptosis to MAC-T cells, we assessed the mRNA expression levels of the apoptosis related genes such as caspase8 (CASP8), Bcl- $x L$, and Bax (Figure 1D, E). Expression of CASP8 in the high-glucose treated group was significantly higher at 1 and $8 \mathrm{~d}$ (Figure 1D). However, expression of CASP8 in the high-glucose group at 2 and $4 \mathrm{~d}$ was significantly lower than that in the no-glucose group (Figure 1D). Although expression levels of CASP8 are significantly different in each group, the maximum difference of gene expression was less than two fold (Figure 1D) and there is no significant difference of $B c l-x L: B a x$ ratio in each group indicating that the levels of glucose before induction of differentiation did not affect apoptosis of MAC-T cells (Figure 1E).

Expression levels of the glucose transporter (GLUT) 1, 4, 8, and 12 were analyzed. Results indicated that there are no significant differences of expression of GLUT 1, 4, 8, and 12 genes in each group 1, 2, 4, and $8 \mathrm{~d}$ after differentiation (Figure 2A, B, C, D).

In this study, expression of IGF-1 receptor gene in low-glucose group was significantly higher than that in the other groups at 2,4 , and $8 \mathrm{~d}$ (Figure 3A). Especially, expression of IGF-1 receptor gene was highest in the low-glucose group at $2 \mathrm{~d}$ of differentiation (Figure 3A). Expression levels of the oxytocin receptor in the low-glucose group were significantly higher than those in the no-glucose and high-glucose groups at 1, 2, 4, and $8 \mathrm{~d}$ (Figure 3B). Expression of casein, including $\alpha S 1, \alpha S 2$, and $\beta$ genes, was evaluated in all treatment groups at 1,2, 4, and $8 \mathrm{~d}$ (Figure 3C, $\mathrm{D}, \mathrm{E})$. In case of aS1, expression levels in the low-glucose group were significantly higher than those in the other groups at 1 and $2 \mathrm{~d}$. However, no significant differences in gene expressions of $\alpha \mathrm{S} 1$ and $\beta$ casein were observed at 4 and $8 \mathrm{~d}$. Cells treated with low-glucose exhibited an approximately 1.5-fold increase in $\alpha \mathrm{S} 2$ casein mRNA expression at $1 \mathrm{~d}$ compared to that in other groups (Figure 3D). Exposure to low-glucose increased the expression of $\beta$-casein mRNA with 3 -fold higher expression at $1 \mathrm{~d}$ and over 3.5-fold higher expression at $2 \mathrm{~d}$ than that in the control group (Figure 3E). In addition, the protein expression levels of total bovine casein as determined by western immunoblot revealed that casein expression was higher in the low-glucose condition than in the others (Figure 3F).

\section{DISCUSSION}

Lactation occurs by the secretion of large quantities of proteins, carbohydrates, and lipids. Therefore, proliferation and differen- 
$\mathbf{A}$

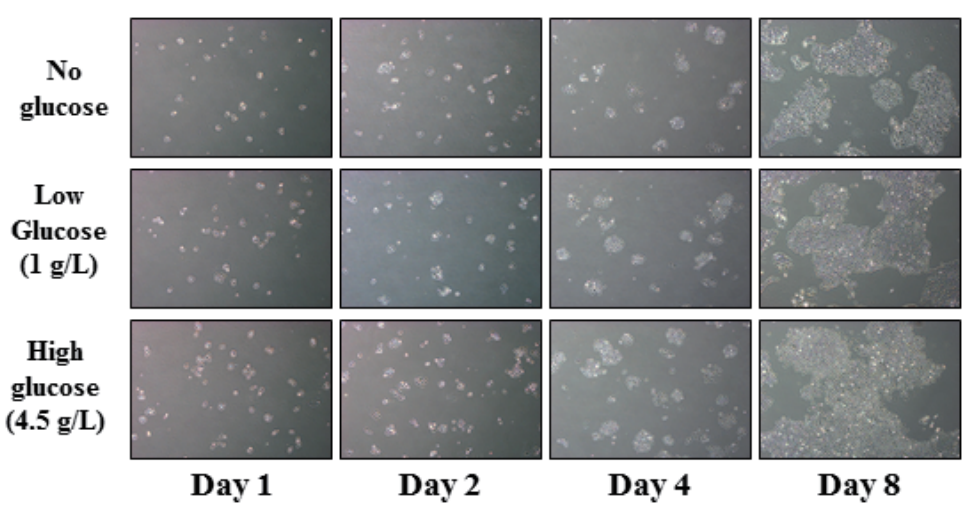

B

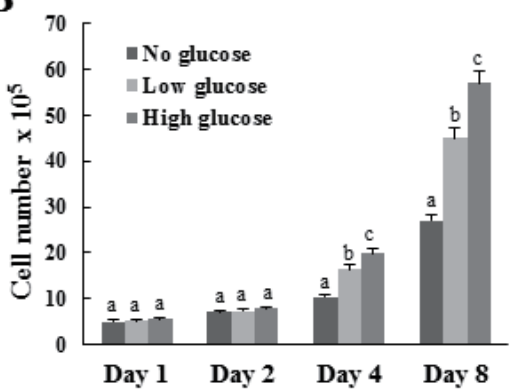

C

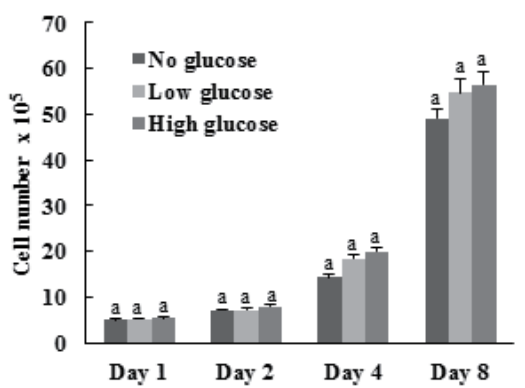

D

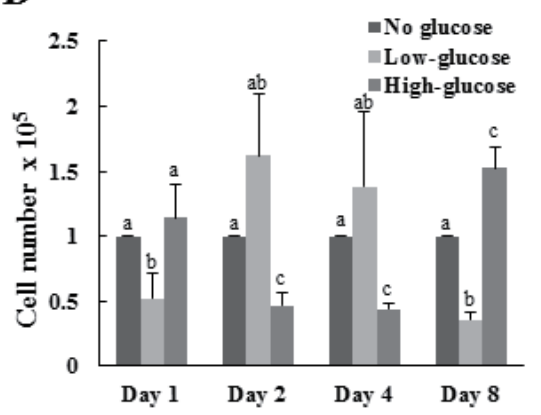

$\mathbf{E}$

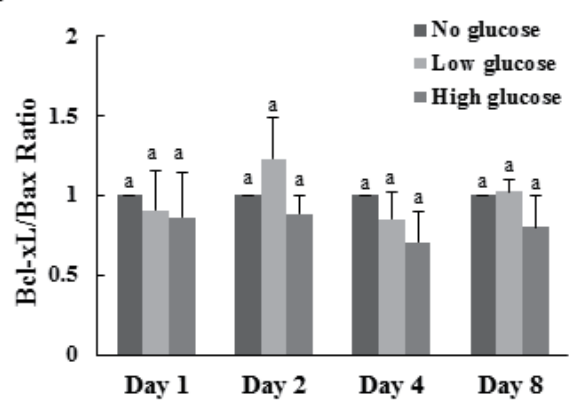

Figure 1. Effects of glucose level on the proliferation and apoptosis of MAC-T cells. The cells were cultures in none, low and high (0, 1, and $4.5 \mathrm{~g} / \mathrm{L}) \mathrm{glucose}$ DMEM media. MAC-T cells which treated different level of glucose were observed by microscope on 1, 2, 4, and $8 \mathrm{~d}$ (A). The cell proliferations of the treatment groups before (B) and after (C) differentiation induction was analyzed by cell counting. Apoptotic effects by different glucose level were determined by real-time, reverse transcription-PCR and GAPDH was use as the endogenous housekeeping gene (D, E). Expression of the apoptosis-related genes caspase8 (D) BCl-XL and Bax (E) in MAC-T cells was measured at 1, 2, 4, and $8 \mathrm{~d}$ after induction of differentiation. Results are expressed as the $B C l-x L$ :Bax mRNA ratios (E). Each experiment was repeated 3 times. All values are expressed as mean \pm standard error of the mean. MAC-T, mammary alveolar; DMEM, Dulbecco's modified Eagle's medium; PCR, polymerase chain reaction; GAPDH, glyceraldehyde 3-phosphate dehydrogenase. Each experimental group indicated a-c to significant differences between each treatment for same days $(p<0.05)$.

tiation of mammary gland cells are very essential biological events. Bovine MAC-T cells, which are derived from the bovine mammary gland, have the ability to differentiate into $\beta$-casein secreting cells when treated with PRL. However, the efficiency of differentiation induction of MAC-T cells into $\beta$-casein-secreting cells by PRL is only approximately 30\% [25]. Our previous study revealed that treatment of PRL with RA to MAC-T cells dramatically increases the efficiency of differentiation induction of MAC-T cells [24]. Therefore, in this study, we used a mixture of PRL, RA, insulin, and hydrocortisone for differentiating MAC-T cells as described previously [24]. Previous studies used $1 \mathrm{~g} / \mathrm{L}$ as low-glucose, $2.5 \mathrm{~g} / \mathrm{L}$ as intermediate, and $4.5 \mathrm{~g} / \mathrm{L}$ as high-glucose concentrations based on the physiological requirement of glucose [26]. Therefore, the concentration of glucose in culture media in this study was determined to be $0 \mathrm{~g} / \mathrm{L}$ as no-glucose, $1 \mathrm{~g} / \mathrm{L}$ as low-glucose and $4.5 \mathrm{~g} / \mathrm{L}$ as high-glucose.

It is well reported that the $B c l-x L: B a x$ mRNA ratio is a more precise evaluation of apoptosis than the absolute concentration of either Bcl- $x L$ mRNA or Bax mRNA [27]. Therefore, the ratio of $B c l-x L$ :Bax gene expression was analyzed in all experimental groups at $1,2,4$, and $8 \mathrm{~d}$ after differentiation induction. Our results indicated that glucose concentration did not affect 
A

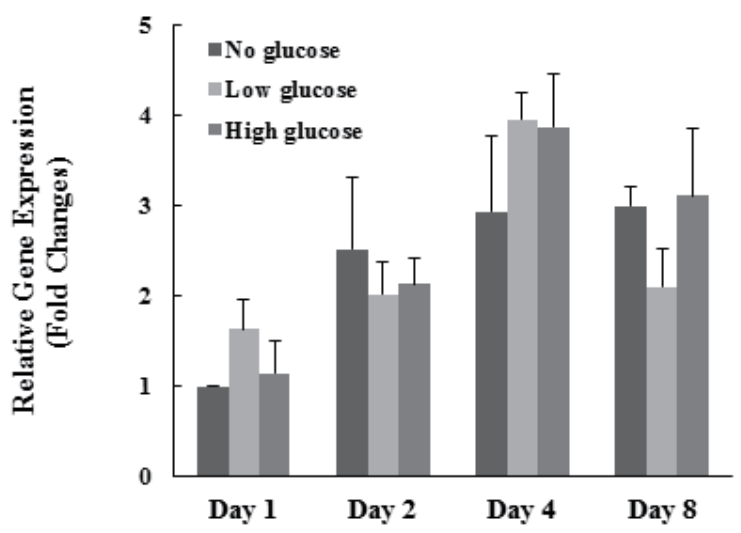

C

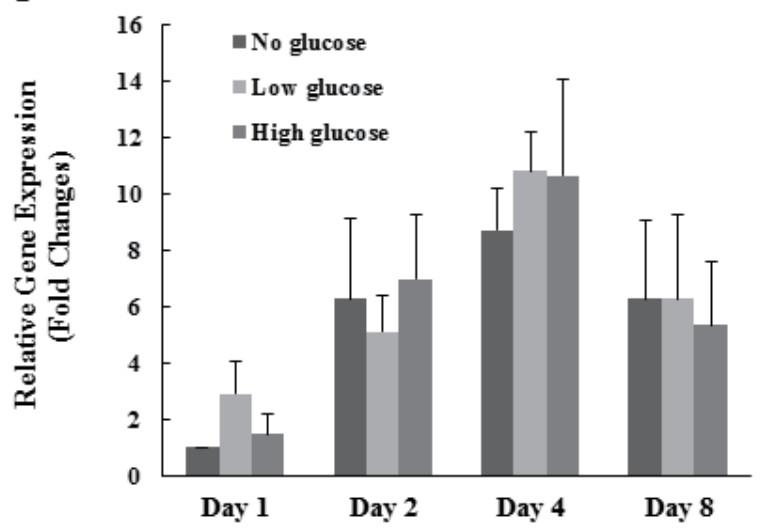

B

GLUT 4

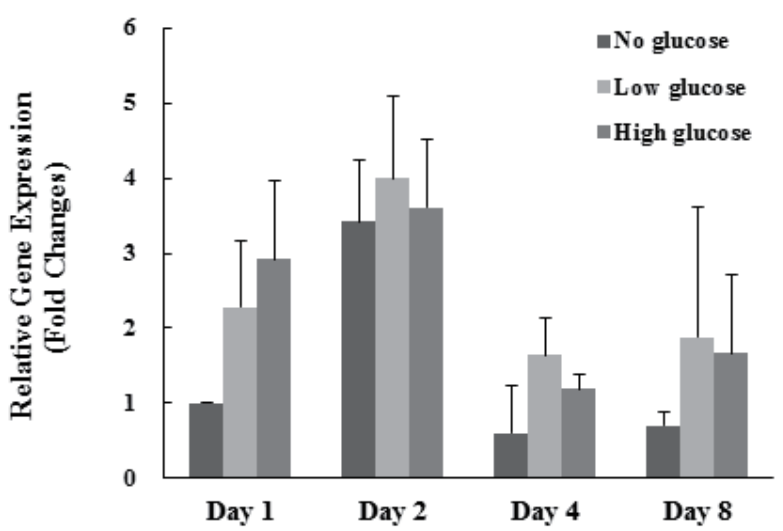

GLUT 12

D

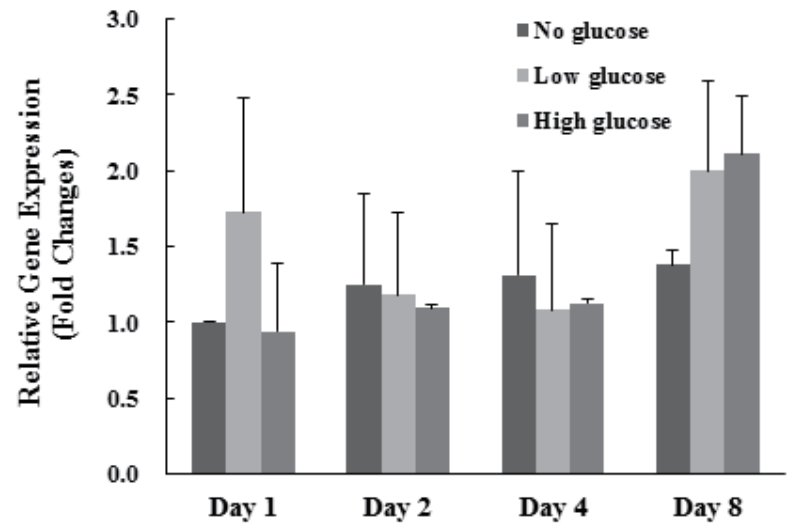

Figure 2. Effects of glucose level on the expression of glucose transporters in differentiated MAC-T cells. Expression levels of mammary gland specific glucose transporters (1, 4, 8, and 12) genes were determined by real-time, reverse transcription-PCR and GAPDH was used as the endogenous housekeeping gene. Expressions of GLUT 1 (A), 4 (B), 8 (C), and 12 (D) genes in MAC-T cells was measured at 1, 2, 4 and $8 \mathrm{~d}$ after induction of differentiation. Each experiment was repeated 3 times. All values are expressed as mean \pm standard error of the mean. MAC-T, mammary alveolar; PCR, polymerase chain reaction; GAPDH, glyceraldehyde 3-phosphate dehydrogenase; GLUT, glucose transporter.

apoptosis in cultured MAC-T cells.

It is well known that there are two types of glucose transporters such as facilitative glucose transporters (GLUT 1 to 12 and $\mathrm{H}^{+} /$ myo-inositol transporter) and sodium-dependent (sodium-dependent transport proteins 1 to 5 , sodium myo-inositol transporter 2 and sodium monocarboxylate transpoter 2) [28]. Among them, GLUT 1, 4, 8, 12 are mammary gland specific glucose transporters. Interestingly, glucose concentration does not regulate expression of the glucose transporter but inhibits glucose phosphorylation [29]. Our results also concur with those of the previous study, showing that different concentrations of glucose did not change the expression levels of mammary specific glucose transporter genes such as GLUT 1, 4, 8, and 12 .

The IGF-1 is an essential biological factor for sustaining life with various functions. Previous studies intensely revealed the role of growth hormone and IGF-1 in mammary gland development. Briefly, growth hormone $(\mathrm{GH})$ stimulates expression of IGF-1 mRNA and then IGF-1 mimics the action of GH in mammary cell differentiation and development [30,31]. Additionally, IGF- 1 and 2 regulate the expression of $\beta$-casein in cultured mammary epithelial cells [32]. Our results correlate with previous reports where expression of casein $\mathrm{mRNA}$ is shown to be proportional to expression of IGF-1 mRNA in cultured MAC-T cells [31].

Previous studies have described that oxytocin is one of the major endocrines in lactation. In addition, the presence of oxytocin receptor in mammary epithelial cells and its dynamic changes enable the binding of oxytocin to secretory cells during lactation in mammalian species [33].

Expression of the milk protein casein is an important indicator of the differentiation of MAC-T cells [34]. Our analysis showed that a low-glucose environment to MAC-T cells increases expression of $\alpha \mathrm{S} 1$-casein, $\alpha \mathrm{S} 2$-casein and $\beta$-casein. Thus, these data may support that surplus glucose is unnecessary and/or even disadvantageous for differentiating mammary secretory cells. 


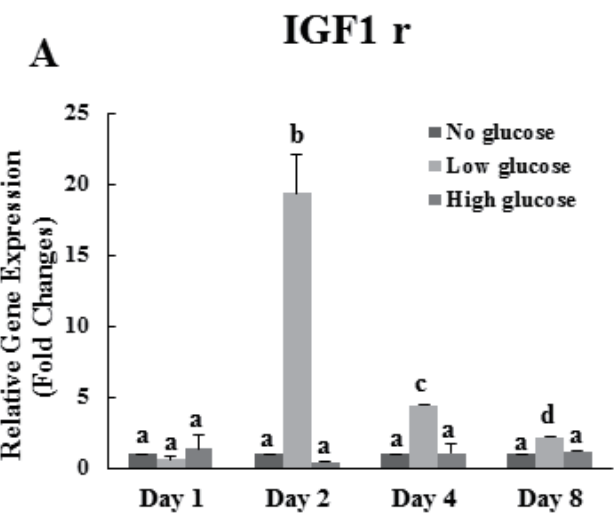

\section{B Oxytocin $\mathbf{r}$}
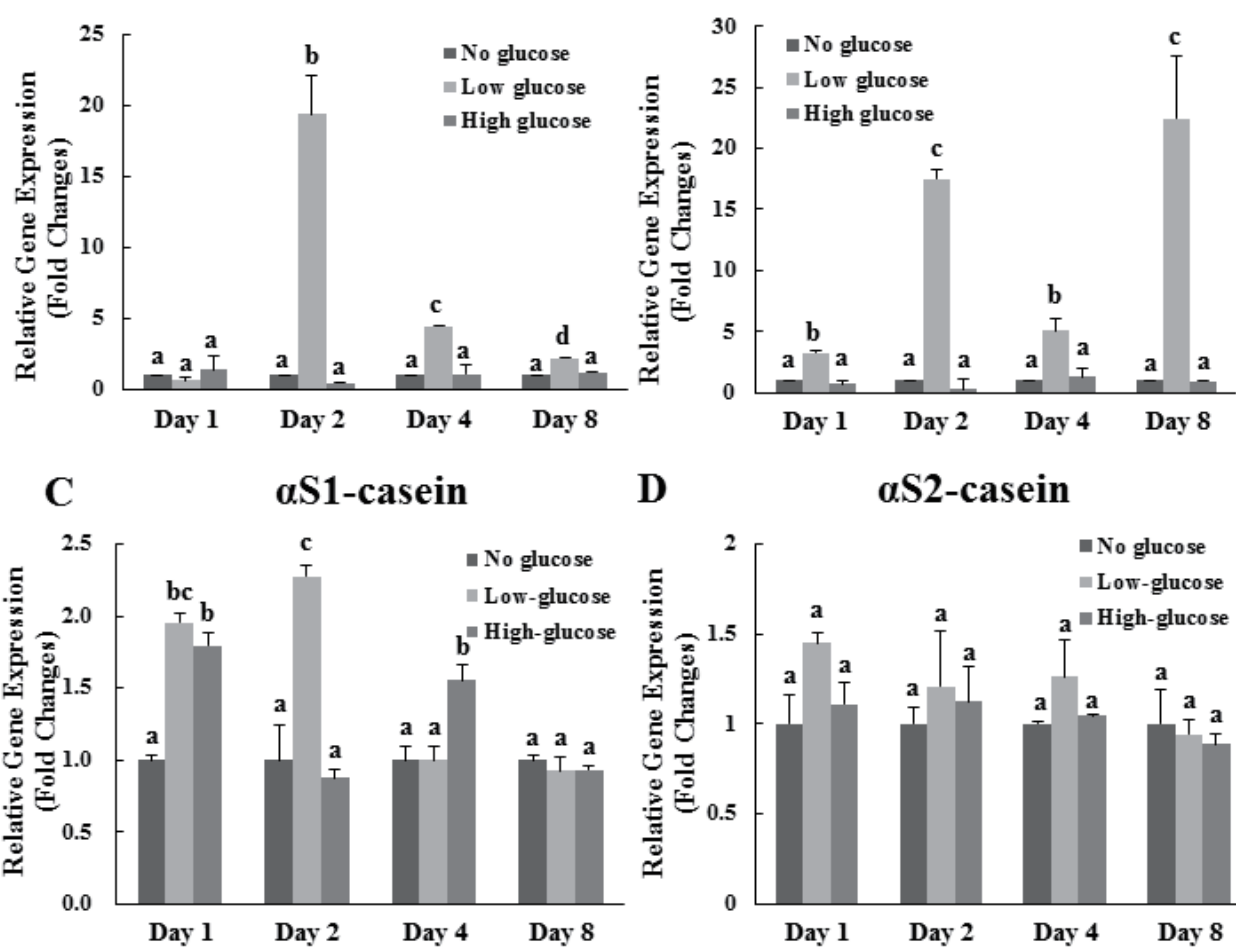

D $\quad \alpha$ S2-casein
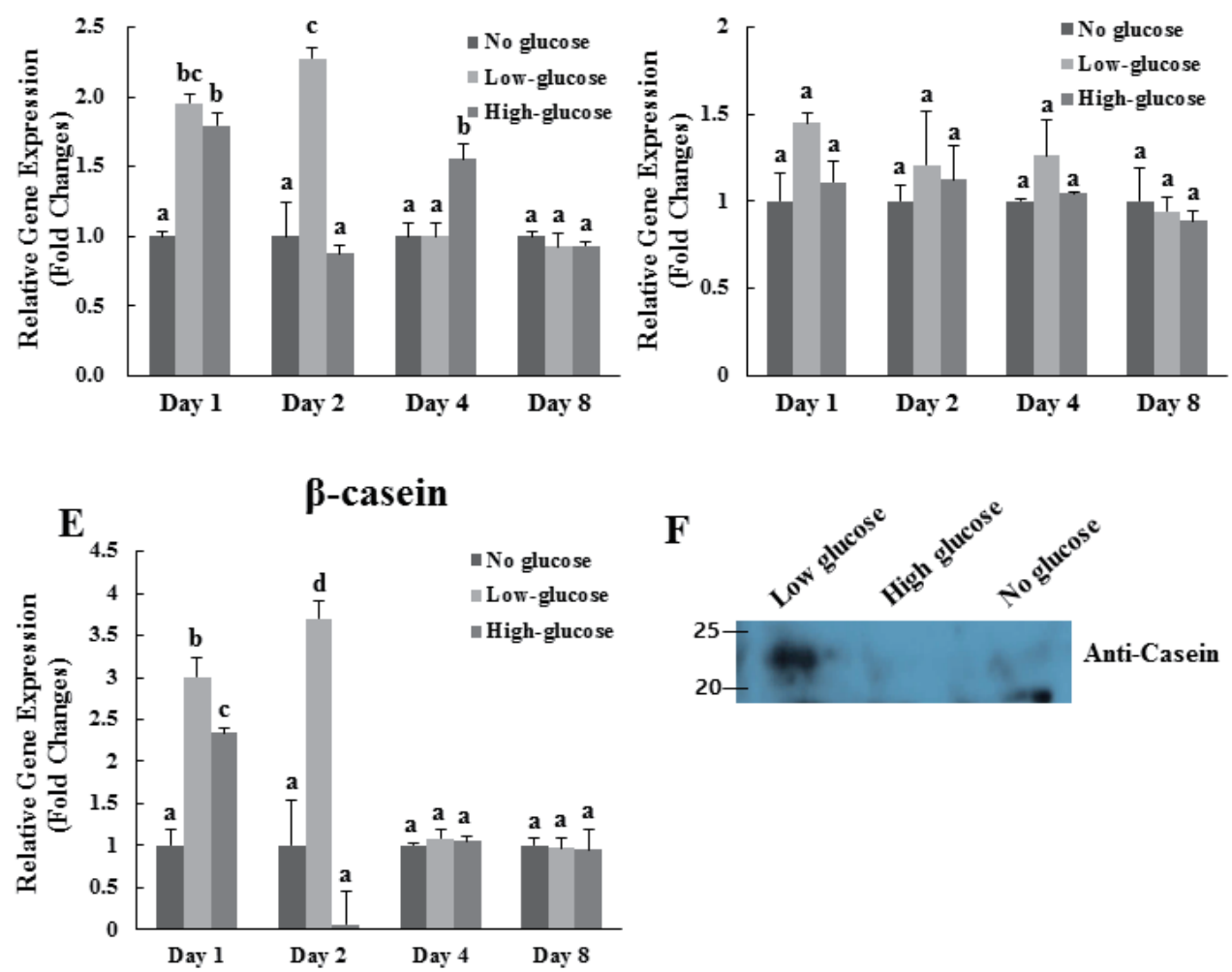

Figure 3. Effects of glucose level on the expression of bovine IGF-1 receptor, oxytocin receptor, aS1-casein, aS2-casein, and $\beta$-casein genes in differentiated MAC-T cells. Expression levels of genes were determined by real-time, reverse transcription-PCR and GAPDH was used as the endogenous housekeeping gene. Expression of the mammary cell development related gene IGF-1 receptor (A), and lactation related gene Oxytocin receptor (B) in MAC-T cells was measured at 1, 2, 4, and $8 \mathrm{~d}$ after induction of differentiation. Expressions of bovine $\alpha \mathrm{S} 1$-casein (C), $\alpha \mathrm{S} 2$-casein (D), and $\beta$-casein (E) genes were analyzed at 1, 2, 4, and $8 \mathrm{~d}$ after induction of differentiation. Expression of bovine total casein in cultured media (F) was identified at $4 \mathrm{~d}$ after induction of differentiation. Each experiment was repeated 3 times. All values are expressed as mean \pm standard error of the mean. IGF-1, insulin like growth factor-1; MAC-T, mammary alveolar; PCR, polymerase chain reaction; GAPDH, glyceraldehyde 3-phosphate dehydrogenase. Each experimental group indicated a-c to significant differences between each treatment for same days $(p<0.05)$.

In conclusion, the present results are consistent with the effects of glucose level to expression of casein genes in MAC-T cells, and the expression levels of mammary cell development related gene and lactation related gene. Although a high-glucose environment enhances proliferation of MAC-T cells, low-glucose treatment increases expression of casein genes. The precise mechanism by which levels of glucose affect the secretion of milk from mammary epithelial cells clearly requires further study. However, our results may be interesting to understand the effects of glucose on MAC-T cell differentiation more precisely and may suggest ways of enhancing the glucose utilization for improving efficiency of milk productivity and its connected biological effects.

\section{CONFLICT OF INTEREST}

We certify that there is no conflict of interest with any financial 
organization regarding the material discussed in the manuscript.

\section{ACKNOWLEDGMENTS}

This work was carried out with the support of the Cooperative Research Program for Agriculture Science \& Technology Development (Project No. PJ010924), Rural Development Administration, Republic of Korea.

\section{REFERENCES}

1.Cardenas H, Carvajal A, Utreras E, et al. Lactation inhibits the potentiating effect of galanin upon the $\mathrm{GnRH}$-induced $\mathrm{LH}$ release observed in diestrous-1 rat. Biol Res 1998;31:351-8.

2.Threadgold LC, Kuhn NJ. Glucose-6-phosphate hydrolysis by lactating rat mammary gland. Int J Biochem 1979;10:683-5.

3.Kuhn NJ, Carrick DT, Wilde CJ. Lactose synthesis: the possibilities of regulation. J Dairy Sci 1980;63:328-36.

4.Stacey A, Schnieke A, Kerr M, et al. Lactation is disrupted by alphalactalbumin deficiency and can be restored by human alpha-lactalbumin gene replacement in mice. Proc Natl Acad Sci USA 1995;92: 2835-9.

5.Xiao CT, Cant JP. Relationship between glucose transport and metabolism in isolated bovine mammary epithelial cells. J Dairy Sci 2005; 88:2794-805.

6.Rulquin $\mathrm{H}$, Rigout $\mathrm{S}$, Lemosquet $\mathrm{S}$, Bach $\mathrm{A}$. Infusion of glucose directs circulating amino acids to the mammary gland in well-fed dairy cows. J Dairy Sci 2004;87:340-9.

7.Brown EG, Vandehaar MJ, Daniels KM, et al. Effect of increasing energy and protein intake on mammary development in heifer calves. J Dairy Sci 2005;88:595-603.

8.Al-Trad B, Reisberg K, Wittek T, et al. Increasing intravenous infusions of glucose improve body condition but not lactation performance in midlactation dairy cows. J Dairy Sci 2009;92:5645-58.

9.Blum JW, Schnyder W, Kunz PL, et al. Reduced and compensatory growth: endocrine and metabolic changes during food restriction and refeeding in steers. J Nutr 1985;115:417-24.

10. Daniels KM, McGilliard ML, Meyer MJ, et al. Effects of body weight and nutrition on histological mammary development in Holstein heifers. J Dairy Sci 2009;92:499-505.

11. Zavizion B, van Duffelen M, Schaeffer W, Politis I. Establishment and characterization of a bovine mammary epithelial cell line with unique properties. In Vitro Cell Dev Biol Anim 1996;32:138-48.

12. Huynh HT, Robitaille G, Turner JD. Establishment of bovine mammary epithelial cells (MAC-T): an in vitro model for bovine lactation. Exp Cell Res 1991;197:191-9.

13. Thorn SR, Purup S, Vestergaard M, et al. Regulation of mammary parenchymal growth by the fat pad in prepubertal dairy heifers: role of inflammation-related proteins. J Endocrinol 2008;196:539-46.

14. Purup S, Nielsen TS. Cell-based models to test the effects of milkderived bioactives. Animal 2012;6:423-32.

15. Cohick WS, Turner JD. Regulation of IGF binding protein synthesis by a bovine mammary epithelial cell line. J Endocrinol 1998;157: 327-36.

16. Berry SDK, Nielsen MSW, Sejrsen K, et al. Use of an immortalized bovine mammary epithelial cell line (MAC-T) to measure the mitogenic activity of extracts from heifer mammary tissue: effects of nutrition and ovariectomy. Domest Anim Endocrinol 2003;25: 245-53.

17. Peterson DG, Matitashvili EA, Bauman DE. The inhibitory effect of trans-10, cis-12 CLA on lipid synthesis in bovine mammary epithelial cells involves reduced proteolytic activation of the transcription factor SREBP-1. J Nutr 2004;134:2523-7.

18. Thorn SR, Purup S, Cohick WS, et al. Leptin does not act directly on mammary epithelial cells in prepubertal dairy heifers. J Dairy Sci 2006;89:1467-77.

19. Bruzelius K, Purup S, James P, Önning G, Åkesson B. Biosynthesis of selenoproteins in cultured bovine mammary cells. J Trace Elem Med Biol 2008;22:224-33.

20. Sorensen BM, Chris Kazala E, Murdoch GK, et al. Effect of CLA and other C18 unsaturated fatty acids on DGAT in bovine milk fat biosynthetic systems. Lipids 2008;43:903-12.

21. Zhou Y, Capuco AV, Jiang H. Involvement of connective tissue growth factor (CTGF) in insulin-like growth factor-I (IGF1) stimulation of proliferation of a bovine mammary epithelial cell line. Domest Anim Endocrinol 2008;35:180-9.

22. Naso LG, Lezama L, Rojo T, et al. Biological evaluation of morin and its new oxovanadium(IV) complex as antio-xidant and specific anti-cancer agents. Chem Biol Interact 2013;206:289-301.

23. Wang B, Zhao M-z, Cui N-p, et al. Krüppel-like factor 4 induces apoptosis and inhibits tumorigenic progression in SK-BR-3 breast cancer cells. FEBS Open Bio 2015;5:147-54.

24. Lee HY, Heo YT, Lee SE, et al. Short communication: retinoic acid plus prolactin to synergistically increase specific casein gene expression in MAC-T cells. J Dairy Sci 2013;96:3835-9.

25. Lyons WR. Hormonal synergism in mammary growth. Proc R Soc Lond B Biol Sci 1958;149:303-25.

26. Li H, Gu Y, Zhang Y, Lucas MJ, Wang Y. High glucose levels downregulate glucose transporter expression that correlates with increased oxidative stress in placental trophoblast cells in vitro. J Soc Gynecol Invest 2004;11:75-81.

27. Gross A. BCL-2 proteins: regulators of the mitochondrial apoptotic program. IUBMB Life 2001;52:231-6.

28. Oswiecimska J, Suwala A, Swietochowska E, et al. Serum omentin levels in adolescent girls with anorexia nervosa and obesity. Physiol Res 2015;64:701-9.

29. Viñals F, Gross A, Testar X, et al. High glucose concentrations inhibit glucose phosphorylation, but not glucose transport, in human endothelial cells. Biochim Biophys Acta (BBA) - Mol Cell Res 1999;1450: 119-29.

30. Sun Z, Shushanov S, LeRoith D, Wood TL. Decreased IGF type 1 receptor signaling in mammary epithelium during pregnancy leads to reduced proliferation, alveolar differentiation, and expression of insulin receptor substrate (IRS)-1 and IRS-2. Endocrinology 2011; 
152:3233-45.

31. Kleinberg DL, Barcellos-Hoff MH. The pivotal role of insulin-like growth factor I in normal mammary development. Endocrinol Metab Clin North Am 2011;40:461-71, vii.

32. Shushanov SS. Insulin-like growth factors 1 and 2 regulate expression of $\beta$-casein in vitro in mouse mammary epithelial cells. Bull Exp
Biol Med 2011;152:202-5.

33. Lollivier V, Marnet PG, Delpal S, et al. Oxytocin stimulates secretory processes in lactating rabbit mammary epithelial cells. J Physiol 2006;570:125-40.

34. Ginger MR, Grigor MR. Comparative aspects of milk caseins. Comp Biochem Physiol B Biochem Mol Biol 1999;124:133-45. 